\title{
The Formation of Living and Non-Living Superordinate Concepts as a Function of Individual Differences
}

Solène Kalénine and Françoise Bonthoux

\author{
(2) OpenEdition \\ Journals \\ Electronic version \\ URL: http://journals.openedition.org/cpl/1066 \\ DOI: $10.4000 / \mathrm{cpl} .1066$ \\ ISSN: $1379-6100$ \\ Publisher \\ Centre PsyCLÉ
}

\section{Electronic reference}

Solène Kalénine and Françoise Bonthoux, «The Formation of Living and Non-Living Superordinate Concepts as a Function of Individual Differences », Current psychology letters [Online], 19, Vol. 2, 2006 | 2006, Online since 14 December 2006, connection on 08 September 2020. URL : http:// journals.openedition.org/cpl/1066 ; DOI : https://doi.org/10.4000/cpl.1066

This text was automatically generated on 8 September 2020

(C) All rights reserved 


\title{
The Formation of Living and Non- Living Superordinate Concepts as a Function of Individual Differences
}

\author{
Solène Kalénine and Françoise Bonthoux
}

Received December 12, 2005

Revised July 18,2006

Accepted September 28, 2006

On line December 14, 2006

Introduction

Individual differences in the way children prefer categorizing objects have rarely been studied per se. Nevertheless, there are some indirect empirical evidence in this issue. Bauer \& Mandler (1979) found that very young children (16-19 month-old) can match objects either taxonomically or thematically following a brief training phase. A study conducted by Waxman \& Namy (1997) also revealed that 2-to 4-year-old children can understand both taxonomic and thematic relations and appear to adjust their responses according to the demands of the task. More relevant to this issue is the work of Dunham \& Dunham (1995). In experiment 1, three-year-old children were presented with a standard picture (e.g., a dog) and 3 matching pictures including a basic-level taxonomic match (e.g., another dog), a thematic match (e.g., a bone) and a foil (e. g., a pen). The child had to "find another one the same as" the standard picture. Results indicated that whereas most children showed a basic-level taxonomic tendency, some children exhibited a thematic tendency. These findings clearly demonstrate that young children's categorical choices depend on individual sensitivity to each type of relation, these tendencies being relatively stable over time. In addition, a longitudinal study (Dunham \& Dunham, 1995, experiment 3) showed that a selective interest in relations among objects as indexed by early functional-relational play at one year and the use of relational terms at two years were both antecedents of the thematic tendency at 3 years. Alternatively, a selective interest in objects' identity as indexed by pointing gestures at one year and the use of nouns and adjectives at two years were both 
antecedents of the basic-level taxonomic tendency at 3 years. Thus, individual tendencies in children's categorization can be predicted by several aspects of children's sensorimotor and linguistic behavior in the first two years of life.

Moreover, children's categorization seems to depend on situations. Numerous studies have revealed task-effects (Blaye, Bernard-Peyron, \& Bonthoux, 2000; Markman, Cox, \& Machida, 1981), verbal labels (Gelman \& Markman, 1987; Gentner \& Namy, 1999; Golinkoff, Shuff-Bailey, Olguin, \& Ruan, 1995; Liu, Golinkoff, \& Sak, 2001; Markman \& Hutchinson, 1984; Waxman \& Gelman, 1986), instructions (Osborne \& Calhoun, 1998; Waxman \& Namy, 1997) and training (Deak \& Bauer, 1995; Smiley \& Brown, 1979). Altogether, results suggest inter- and intra-individual variability in categorization behaviors. An assumption made by Wisniewski \& Bassok (1999) is that different processes underlie taxonomic and thematic relations: The variability observed in categorization behaviors might be linked with differences in object processing. Using similarity and thematic judgments in adults, Wisniewski \& Bassok (1999) revealed that basic-level taxonomic relations predominantly activate a comparison process between objects whereas thematic relations mainly activate an integration process. Indeed, taxonomically related objects (e.g., poodle-German shepherd) share many dimensions on which they can be compared (e.g., name, size, shape, parts). Within the taxonomic hierarchy, basic-level categories that possess many common and distinctive features (Rosch, Mervis, Gray, Johnson, \& Boyes-Braem, 1976) might lead individuals to predominantly compare items. On the contrary, thematically related objects (e.g., apples-basket) are more likely to be integrated into a joint theme or scenario (put apples in a basket). Nevertheless, Wisniewski \& Bassok (1999)'s results also showed that comparison was sometimes used for thematic relations and integration with taxonomic relations.

Indeed, conceptual development might rest at least on two processes, their relative implication varying according to individuals and situations (Lautrey, 1990, 2003; Lautrey \& Caroff, 1997). The role of variability in cognitive development is also a cornerstone of the differential approach of Siegler (Siegler \& Jenkins, 1989; Siegler \& Shipley, 1995) who claims that cognitive development is not a 1: 1 correspondence between children's age and the strategy they use to resolve a task. On the contrary, children of a given age range use a variety of strategies, the selection of a particular strategy depending on the children's preferences, their own experience, the effectiveness of each strategy and the problem considered. This selection mechanism is assumed to generate cognitive development by leading to greater use of processes that have been useful under the particular circumstances encountered by the child.

As concerns concept formation, this approach would imply that at any age, both processes (comparison/integration) and relations (basic-level taxonomic/thematic) are available. Children can predominantly use either a comparison process and mainly rely on basic-level taxonomic relations or an integration process and mainly rely on thematic relations, depending on their individual tendencies and the situations. Moreover, different kinds of relations might be more or less available as a function of the semantic domain. This assumption is based on another range of researches in the domain of language and semantic memory. Indeed, data from studies with braindamaged patients (Capitani, Laiacona, Mahon, \& Caramazza, 2003) and with normal adults (Cree \& McRae, 2003; Devlin, Gonnerman, Andersen, \& Seidenberg, 1998; Farah \& McClelland, 1991; Garrard, Lambon Ralph, Hodges, \& Patterson, 2001; Laws, Humber, Ramsey, \& McCarthy, 1995; Sartori \& Job, 1988), suggest that perceptual information is 
more central for the understanding of living things whereas contextual and functional information is more central for non-living things. This distinction observed in tasks such as property verification or property generation in adults is likely to result from the frequency and the way people interact with different kinds of objects. However, few results are available in children. Hughes, Woodcock, \& Funnell (2005) asked "what is a -_-_" questions to children aged from 3 to 7 years. Results showed that perceptual properties dominate responses to living things when compared with functional properties (defined as "the purpose of objects") whereas functional properties outnumbered perceptual responses for non-living things. Moreover, some categorization studies in children have highlighted the greater weight of functional properties for artefacts and perceptual properties for living things (Boyer, Bedoin, \& Honore, 2000; Hughes et al., 2005; Kemler Nelson, 1995; Kemler Nelson, Chan Egan, \& Holt, 2004; Kemler Nelson, Frankenfield, Morris, \& Blair, 2000; Kemler Nelson, Russell, \& Jones, 2000; Scheuner \& Bonthoux, 2004), even if both information are commonly recruited. Consequently, these findings suggest that comparison of several entities along perceptual properties might be predominantly used to form superordinate categories of living things. On the other hand, the integration of contextually linked artefacts might facilitate the formation of superordinate non-living categories. Furthermore, the use of perceptual cues to discriminate and categorize objects seems to precede infants' resorting to functional cues (Madole, Oakes, \& Cohen, 1993). These data support the interpretation of an earlier structuration of the living domain (Boyer et al., 2000; Gelman, Coley, Rosengren, Hartman, \& Pappas, 1998). Thus, we predicted that individual tendencies and domains would both influence children's categorization behaviour (Bonthoux, 2001; Bonthoux, Scheuner, \& Roll, 2003).

The present study aims at testing this hypothesis in 3-year-old children. Three-yearolds were selected in order to replicate Dunham and Dunham (1995)'s findings, namely individual differences in categorization behaviours observed in a matching task contrasting basic-level taxonomic and thematic relations. In a first session, individual sensitivity to basic level taxonomic relations versus thematic relations was investigated in a matching task. Taxonomic choices were expected to dominate since the taxonomic relation proposed was at the basic level. However, we predicted individual differences in children's categorization behaviour at this age, as found by Dunham \& Dunham (1995) with a similar task. In a second session, the understanding of superordinate concepts such as animals or tools was assessed. Performances were expected to vary as a function of children's individual sensitivity and concept domains. Specifically, children most sensitive to basic-level taxonomic relations in session 1 should perform better when matching living things than non-living things at the superordinate level in session 2. On the contrary, a greater sensitivity to thematic relations should facilitate the categorization of non-living things.

MethodParticipants

Sixty children aged between 3 and 4 years (mean age: 3 years 6 months in the first session) took part in this study. Twenty-seven were boys and thirty-three were girls. All were attending preschool for the first year. A further 24 children of the same age range and 20 adults were recruited for pre-tests.

Materials and Procedure

Stimuli 6.5 x 8 centimetres black-and-white drawings selected from a pre-test were used to construct two match-to-sample tasks. 
Pre-test

A pre-test was first conducted to select associations that 3-year-old children usually know. This ensured that children's choices would not be due to the failure to recognize the link between the target(s) and one or several alternatives. During pre-test, each potential target was presented with 3 pictures, one taxonomically or thematically associated to the target and two that were not linked to the target (181 associations in all). Children were told for each trial to choose between the 3 choices "the one that goes with" the target. Only associations that received more than $75 \%$ correct responses were selected as possible items of the two matching tasks.

\section{Session 1}

The aim of the first session was to assess children's individual differences with a basiclevel matching task comprising 20 trials. Each trial involved 4 pictures: a target picture (e.g., a dog) and 3 matching pictures including a basic-level taxonomic match (e.g., another dog), a thematic match (e.g. a bone) and a foil (e.g., a cactus; see Figure 1).
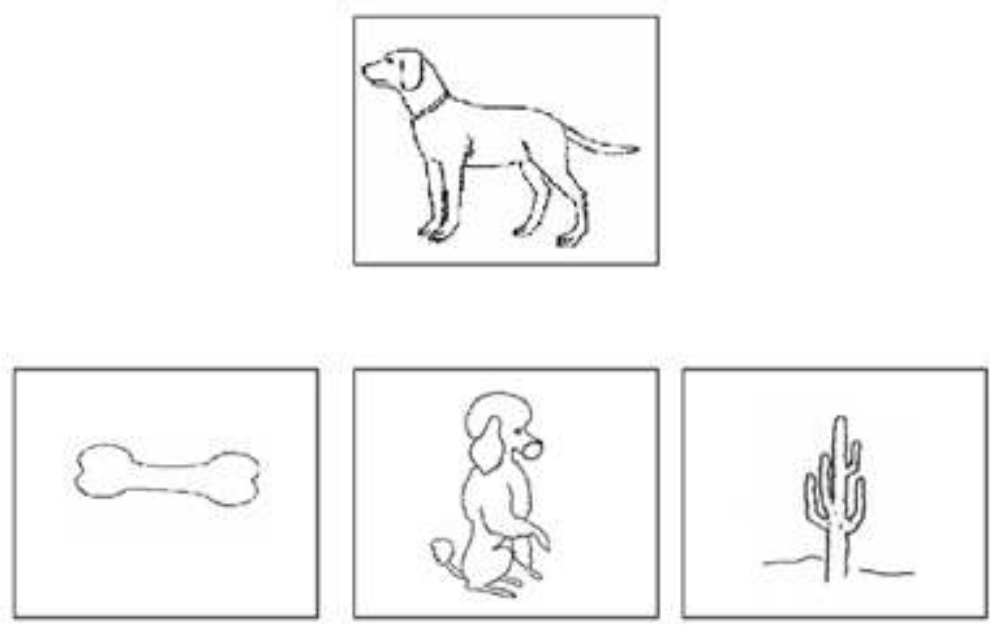

Figure 1: Example of an item in session 1 including a target picture, a thematic match, a basic-level taxonomic match and a foil.

Target pictures represented exemplars of various categories from the living and nonliving domains (see Appendix 1). Ten targets were living things and ten were non-living things. For each of the 20 trials, children were told to choose among the 3 matching pictures the one that "goes best with" the target. Two choices were appropriate: the basic-level taxonomic alternative and the thematic alternative. The duration of session 1 was approximately 5-10 minutes.

Session 2

The second session took place about one month later $(M=26$ days; $S D=6)$. It was designed to examine children's superordinate categorization as a function of the domain of the items and the sensitivity of the children for basic-level taxonomic versus thematic relations as determined in session 1 . The materials and instructions for this session were selected to favour superordinate taxonomic choices. Concerning the materials, Gentner and Namy (Gentner \& Namy, 1999; Namy \& Gentner, 2002) have already shown that engaging children in active comparison of multiple instances of an object category by introducing more than one target picture enables them to form conceptual abstractions (see also Liu et al., 2001). Thus, each of the 18 trials of the 
superordinate matching task involved 5 cards: two target cards taxonomically linked at the superordinate level (e.g., two fruit: an apple and a banana) and 3 choice cards: a superordinate taxonomic match (e.g., grapes), a thematic match (e.g., a basket) and a foil (e.g., a plug; see Figure 2).
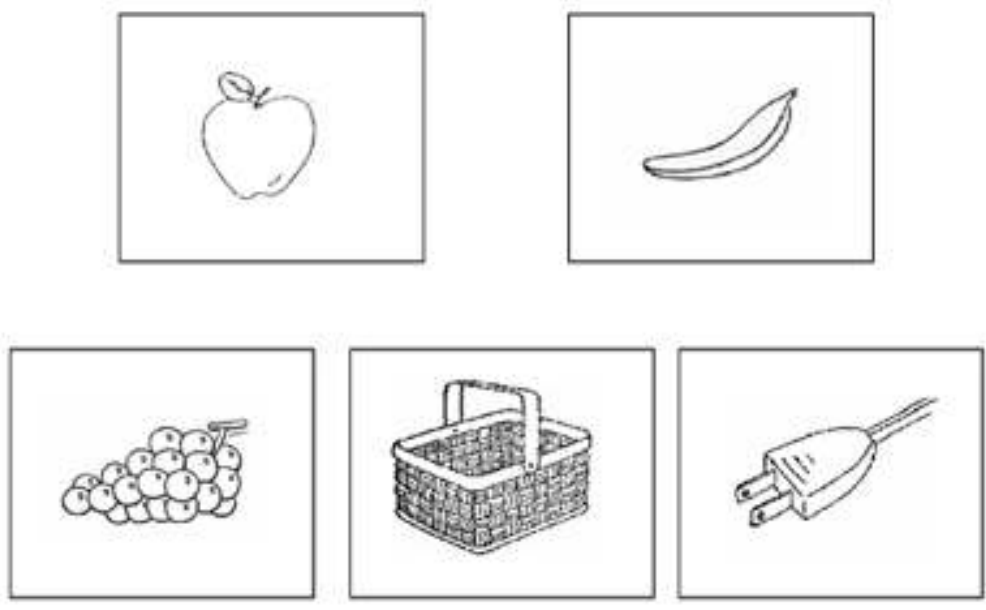

Figure 2: Example of an item in session 2 including a pair of target pictures, a superordinate taxonomic match, a thematic match and a foil.

As in the basic-level task, target pictures represented exemplars of various categories, 9 from the living domain and 9 from the non-living domain (see Appendix 2). In both tasks, the position of the 3 matching cards was counterbalanced across trials and the proportion of living and non-living foils was equivalent for living and non-living target pictures. The order of presentation of the trials was randomly determined. The task was introduced as a card game. The experimenter put the two target cards on the table and explained that she had put these two cards together because "they are the same kind of things, they belong to the same family". Then the 3 matching cards were presented and the child had to "find the other one of the same kind, of the same family" to complete the pair. The duration of session 2 was approximately 10-15 minutes. The task was administered to ten adults who, as expected, performed almost at ceiling level. Moreover, ten additional adults judged the perceptive similarity between each of the targets $(2 \times 18)$ and the corresponding taxonomic matching picture on a continuous scale from 0 to 20 . A mean score of perceptual similarity between 0 and 20 was calculated for each pair of targets. No similarity difference between domains was observed $(t=0.78, p=.45)$.

Results

In session 1, taxonomic, thematic and irrelevant choices were coded for each child. Children whose responses did not differ significantly from chance (more than 4 irrelevant choices out of 20) were removed from the analysis. In session 2, correct responses for living and non-living items were recorded for each of the remaining children. Again, children whose responses did not differ significantly from chance (more than 3 irrelevant choices out of 18) in the second task were removed from the analysis. The final sample included 37 children.

Session 1 
Following Dunham \& Dunham (1995), a taxonomic bias was obtained. However, individual differences in the way children categorize objects were observed. Children made from 4 to 20 taxonomic choices $(M=14.5 ; \mathrm{SD}=4.1)$ and from 0 to 16 thematic choices $(\mathrm{M}=4.8 ; \mathrm{SD}=3.8)$. Individual measures of basic-level taxonomic and thematic choices were converted into Z-scores. Children were considered to have a greater basiclevel taxonomic or thematic sensitivity compared to the sample bias when their taxonomic or thematic Z-score were above one. With this strict criterion, only 6 children showed a greater thematic sensitivity and 8 showed a greater taxonomic sensitivity.

Session 2

A 2 (sensitivity: taxonomic, thematic) x 2 (domain: living things, non-living things) analysis of variance (ANOVA) was conducted on the number of correct responses (superordinate taxonomic choices) made by the 14 children most sensitive to basiclevel taxonomic or thematic relations. As predicted a main effect of domain was observed $\left[F_{1}(1,12)=10.75 ;\right.$ Mse $\left.=1.10, p<.01\right]$ : living items $(M=5.83 ; S D=1.77)$ received more correct responses than non-living items $(M=4.52 ; S D=1.35)$. This effect remained marginally significant in the by-items analysis with perceptive similarity as covariate $\left[F_{2}(1,15)=3.21 ;\right.$ Mse $\left.=582.98, p=.09\right]$. A main effect of sensitivity was also noted $(F(1,12)$

$=5.31 ; \mathrm{Mse}=2.99, p<.05)$ : children most sensitive to taxonomic relations $(M=5.94 ; S D=$ 1.75) made more correct superordinate choices than children most sensitive to thematic relations $(M=4.42 ; S D=1.26)$. The interaction between preference and domain almost reached significance $[F(1,12)=4.12 ;$ Mse $=1.10, p=.06$, see Figure 3]. Tukey posthoc comparisons showed that children most sensitive to taxonomic relations revealed a significant advantage for living things. For children most sensitive to thematic relations, no difference between domains was obtained.

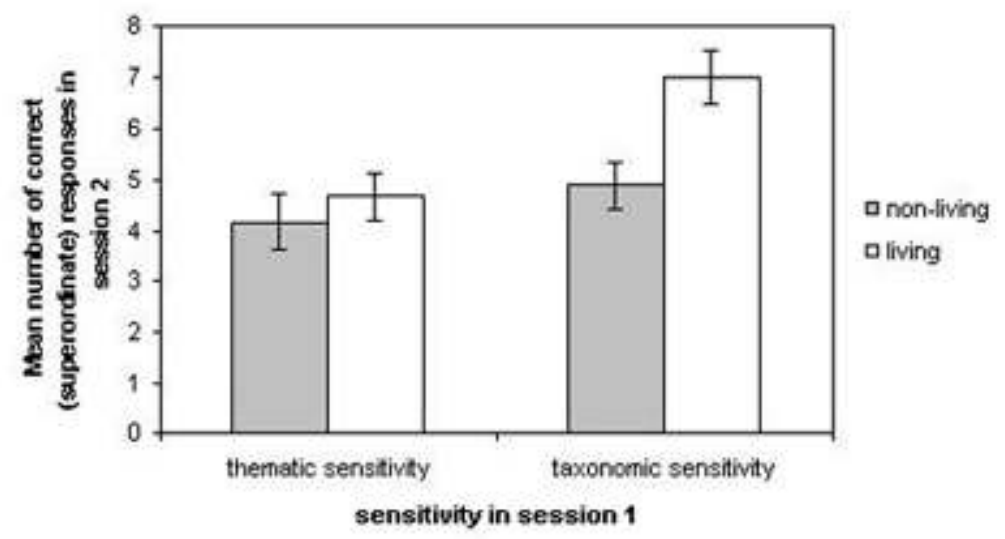

Figure 3: Mean number of correct responses (+/- $1 \mathrm{SE}$ ) in session 2 as a function of sensitivity in session 1 and domain

A similar tendency was expected on the entire sample. In order to check this additional hypothesis, correlations between the number of taxonomic choices in session 1 and the number of correct responses for living and non-living things in session 2 were calculated for the 37 children. As expected, taxonomic choices were positively linked to correct responses for living things $(r=.38 ; \mathrm{p}<.05)$, age (in months) partialled out. However, they were not linked to correct responses for non-living things $(r=.005 ; \mathrm{p}=$. 97). Moreover, no correlation between age in months and number of basic-level 
taxonomic or thematic choices in session 1 was observed (respectively, $r=-.003, p=.98$; $r=.15, p=.38$ ).

Discussion

The purpose of the present study was to examine preschooler's individual differences in a matching task and to link these individual tendencies to superordinate categorization performances as a function of semantic domain. Results of session 1 - a matching task contrasting a thematic match and a basic-level taxonomic match revealed that 3-year-old children's sensitivity can be ordered on a taxonomic-thematic continuum, as reported by Dunham \& Dunham (1995). Individual differences can therefore emerge in a match-to-sample task at this age when few constraints weigh on the situation (Lautrey, 2003) namely wheninstructions do not favour a particular response ("find the one which goes best with the target" in our experiment, "another one the same as the target" in Dunham and Dunham's one). More specifically, some children exhibited a greater sensitivity for either taxonomic or thematic relations. In these situations, it is likely that both relations (e.g. dog-other dog and dog-bone) are activated but not necessarily with the same strength. A possibility is that children's favourite way to deal with their environment during infancy reinforces one connection rather than the other. The role of children's previous experience is highlighted by Dunham and Dunham (1995)'s longitudinal study. They observed positive correlations between matching choices at 3 years and earlier gesture and language behaviour. They interpreted this feature as reflecting individual differences in children's orientation towards objects. The greater sensitivity to basic-level taxonomic or thematic relations might also reflect a predominant use of integration or comparison as proposed by Wisniewski and Bassok (1999). The multiple feedbacks children receive from their environment during infancy (success, mother's validation, etc.) certainly modulate the way they tend to process objects. In the matching task, this may influence the weighting of two co-activated associations and finally determine the child's matching decision.

Session 2 investigated children's ability to categorize at the superordinate level according to children's sensitivity in session 1 and concepts' domain. Overall, superordinate taxonomic grouping of living things outperformed those of non-living things in accord with the hypothesis of an earlier organization of the living domain (Boyer et al., 2000; Gelman et al., 1998). The predicted interaction between children's sensitivity and domain was almost significant $(\mathrm{p}=.06)$. This marginal effect seems meaningful since only 14 children were included in the Anova: the size of the sample has indeed reduced the statistical power of the test. We found that children most sensitive to taxonomic relations better categorized living things whereas performances of children most sensitive to thematic relations did not differ among domains. These different patterns of performances as a function of basic-level taxonomic and thematic individual tendencies do not seem attributable to different developmental levels. First, neither the number of basic-level taxonomic choices nor the number of thematic choices in session 1 was correlated to children's age. Next, the global advantage of children most sensitive to basic-level taxonomic relations was not in the way predictable from developmental hypotheses since basic-level taxonomic concepts are supposed to precede thematic ones in development (Gelman et al., 1998). Therefore, these findings bring empirical evidence to a vision of concept formation involving at least 2 processes more or less implicated according on individuals and situations. 
We suggest that children's sensitivity to basic-level taxonomic/thematic relations, probably resulting from their own experience, may influence the kind of cues involved in concepts formation. A particular sensitivity to basic-level taxonomic relations might reflect a tendency to compare stimuli and favour the detection of common and distinctive properties. Quinn and Eimas $(1996,2000)$ have proposed that concepts could emerge by simply associating several kinds of knowledge with perceptual properties. Even 3 month-old children are indeed able to form basic-level categories (Quinn, Eimas, \& Rosenkrantz, 1993) or superordinate categories (Behl-Chadha, 1996) on the basis of perceptual information. Hence, a developmental way originating in perceptual similarity relations should be particularly efficient for the formation of superordinate natural categories for which perceptual properties are central (Cree \& McRae, 2003; Devlin et al., 1998; Farah \& McClelland, 1991; Garrard et al., 2001; Laws et al., 1995; Sartori \& Job, 1988). Our results clearly reveal the expected efficacy of the taxonomic tendency for natural objects since there was a) a living advantage in children most sensitive to taxonomic relations and $b$ ) a positive correlation between spontaneous taxonomic choices (session 1) and superordinate categorization in this domain.

Additionally, we consider that a particular sensitivity to thematic relations between objects might reflect a tendency to integrate stimuli. This tendency may favour the access to contextualized categories (i.e., slot-fillers such as farm animals or breakfast food) that might derive from thematic relations. A similar developmental hypothesis has already been proposed by Nelson $(1983 ; 1985)$ and more recently by Mandler $(1992$; 2000). Because contextual and functional information are central in the understanding of non-living things (Cree \& McRae, 2003; Devlin et al., 1998; Farah \& McClelland, 1991; Garrard et al., 2001; Laws et al., 1995; Sartori \& Job, 1988), using contextual cues should be particularly efficient for the formation of concepts of artefact concepts. However, our results did not show the expected "non-living" advantage in children most sensitive to thematic relations nor the negative correlation between taxonomic choices (session 1) and superordinate categorization for non-living items (session 2). It is possible that children as young as 3 cannot benefit from their greater sensitivity to thematic relations to form artefacts concepts. Indeed, a sufficient amount of experience is required for the integration of objects that share a contextual or a functional link. If this interpretation is correct, then older children (4-5 year-olds) most sensitive to thematic relations should better categorize artefacts at the superordinate level. Further studies are needed to test this hypothesis.

Another way to explore the link between sensitivity to thematic or basic-level taxonomic relations and categorization performances at the superordinate level might consist in focusing on finer distinctions than the living/non-living dichotomy. The role of action in the understanding of many concepts of artefacts (Buccino et al., 2001; Chao \& Martin, 2000; Creem-Regehr \& Lee, 2005; Gerlach, Law, \& Paulson, 2002; Grafton, Fadiga, Arbib, \& Rizzolatti, 1997; Jonhnson-Frey, 2004; Kellenbach, Brett, \& Patterson, 2003; Myung, Blumstein, \& Sedivy, in press) has been emphasized. These findings suggest that manipulability / non-manipulability which is often confounded with the living/non-living dichotomy (Filliter, McMullen, \& Westwood, 2005) would better differentiate the way objects are processed. Integration and comparison processes could therefore be differentially activated according to object's manipulability. Future research focusing on this dimension will allow to better specifying the way children acquire knowledge about various kinds of objects.

Acknowledgments 
This research was supported by grants from the University Pierre Mendes France of Grenoble and the Centre National de la Recherche Scientifique, Authors thank the preschoolers and their teachers who participated in these studies. They also thank Diane Poulin-Dubois and Marie-Josèphe Tainturier for helpful comments on an earlier version of this paper.

Appendix 1: List of items used in session 1

\begin{tabular}{|l|l|l|l|}
\hline Target & Basic level taxonomic choice & Thematic choice & Foil \\
\hline apple & apple & basket & button \\
\hline castle & castle & knight & bin \\
\hline carrot & carrot & rabbit & shark \\
\hline barge & boat & oars & rolling pin \\
\hline lion & lion cub & cage & grapes \\
\hline lavatory & sink & soap & monkey \\
\hline flower & flower & watering can & ladle \\
\hline mouth & mouth & toothbrush & belt \\
\hline shoe & shoe & foot ball & corn \\
\hline fish & fish & fish bowl & lemon \\
\hline axe & axe & joiner & umbrella \\
\hline dog & dog & bone & cactus \\
\hline hand & fist & pencil & cloud \\
\hline bowl & bowl & slice of bread & lamp \\
\hline pan & pressure cooker & potato & frog \\
\hline squirrel & squirrel & hazelnut & plant \\
\hline car & car & traffic lights & bear \\
\hline hammer & hammer & nail & caterpillar \\
\hline bird & bird & egg & sock \\
\hline jacket & jacket & hanger & cooker \\
\hline
\end{tabular}

Appendix 2: List of items used in session 2

\begin{tabular}{|c|c|c|c|c|}
\hline Target 1 & Target 2 & Superordinate taxonomic choice & Thematic choice & Foil \\
\hline fower & plant & fir & watering can & camel \\
\hline jacket & Swimsuit & shint & hanger & envelope \\
\hline mouth & eye & ear & toothbrush & ball \\
\hline hammer & saw & dnill & nall & bee \\
\hline cartot & tomato & pumpkin & rabbit & jacket \\
\hline house & church & hut & door & drum \\
\hline Lion & elephant & Swan & cage & cherry \\
\hline mitt & pajamas & shorts & ska & mushroom \\
\hline squinel & gost & duck & hazelnut & feeding bottle \\
\hline plane & lomy & boat & suitcase & bottle \\
\hline fish & monkey & mouse & fish bowl & cactus \\
\hline apple & banana & grapes & basket & plug \\
\hline car & train & motor bike & traffic lights & caterpellar \\
\hline cooker & desk & sink & pan & cat \\
\hline hand & foot & $\log$ & pencil & shark \\
\hline glass & colander & fork & straw & boot \\
\hline bird & dolphin & horse & eg9 & hat \\
\hline bed & table & cupboard & pillow & swing \\
\hline
\end{tabular}




\section{BIBLIOGRAPHY}

Behl-Chadha, G. (1996). Basic-level and superordinate-like categorical representations in early infancy. Cognition, 60(2), 105-141.

Blaye, A., Bernard-Peyron, V., \& Bonthoux, F. (2000). Au delà des conduites de catégorisation : Le développement des représentations catégorielles entre 5 et 9 ans. Archives de Psychologie, 68, 59-82.

Bonthoux, F. (2001). The development of categorization. In O. Benga \& M. Miclea (Eds.), Development and cogntion (pp. 59-88). Cluj-Napoca: Presa Universitara Clujeana.

Bonthoux, F., Scheuner, N., \& Roll, N. (2003). Des modes de construction des catégories différenciés selon le domaine. Eléments de réponse chez l'enfant et l'adulte âgé. Cogntion, Brain, Behavior, 7, 91-109.

Boyer, P., Bedoin, N., \& Honore, S. (2000). Relative contributions of kind- and domain-level concepts to expectations concerning unfamiliar exemplars: Developmental change and domain differences. Cognitive Development, 15(4), 457-479.

Buccino, G., Binkofski, F., Fink, G. R., Fadiga, L., Fogassi, L., Gallese, V., et al. (2001). Action observation activates premotor and parietal areas in a somatotopic manner: An fMRI study. European Journal of Neuroscience, 13, 400-404.

Capitani, E., Laiacona, M., Mahon, B., \& Caramazza, A. (2003). What are the facts of categoryspecific deficits? A critical review of the clinical evidence. Cognitive Neuropsychology, 20(3/6), 213-261.

Chao, L. L., \& Martin, A. (2000). Representation of manipulable man-made objects in the dorsal stream. Neuroimage, 12(4), 478-484.

Cree, G. S., \& McRae, K. (2003). Analyzing the factors underlying the structure and computation of the meaning of chipmunk, cherry, chisel, cheese, and cello (and many other such concrete nouns). Journal of Experimental Psychology: General, 132(2), 163-201.

Creem-Regehr, S. H., \& Lee, J. N. (2005). Neural representations of graspable objects: are tools special? Cognitive Brain Research, 22(3), 457-469.

Deak, G., \& Bauer, P. J. (1995). The effects of task comprehension on preschoolers' and adults' categorization choices. Journal of Experimental Child Psychology, 60(3), 393-427.

Devlin, J. T., Gonnerman, L. M., Andersen, E. S., \& Seidenberg, M. S. (1998). Category-specific semantic deficits in focal and widespread brain damage: a computational account. Journal of Cognitive Neuroscience, 10(1), 77-94.

Dunham, P., \& Dunham, F. (1995). Developmental Antecedents of taxonomic and Thematic Strategies at 3 years of age. Developmental Psychology, 31(3), 483-493.

Farah, M. J., \& McClelland, J. L. (1991). A computational model of semantic memory impairment: modality specificity and emergent category specificity. Journal of Expérimental Psychology: General, 120(4), 339-357.

Filliter, J. H., McMullen, P. A., \& Westwood, D. (2005). Manipulability and living/non-living category effects on object identification. Brain and Cognition, 57(1), 61-65. 
Garrard, P., Lambon Ralph, M. A., Hodges, J. R., \& Patterson, K. (2001). Prototypicality, distinctiveness and intercorrelation: Analyses of the semantic attributes of living and non living concepts. Cognitive Neuropsychology, 18(2), 125-174.

Gelman, S. A., Coley, J. D., Rosengren, K. S., Hartman, E., \& Pappas, A. (1998). Beyond labeling: the role of maternal input in the acquisition of richly structured categories. Monographs of the Society for Research in Child Development, 63(1), 1-157.

Gelman, S. A., \& Markman, E. M. (1987). Young children's inductions from natural kinds: the role of categories and appearances. Child Development, 58(6), 1532-1541.

Gentner, D., \& Namy, L. L. (1999). Comparison in the Development of Categories. Cognitive Development, 14(4), 487-513.

Gerlach, C., Law, I., \& Paulson, O. B. (2002). When action turns into words. Activation of motorbased knowledge during categorization of manipulable objects. Journal of Cognitive Neuroscience, 14(8), 1230-1239.

Golinkoff, R. M., Shuff-Bailey, M., Olguin, R., \& Ruan, W. (1995). Young Children Extend Novel Words at the Basic Level: Evidence for the Principle of Categorical Scope. Developmental Psychology, 31(3), 494-507.

Grafton, S. T., Fadiga, L., Arbib, M. A., \& Rizzolatti, G. (1997). Premotor cortex activation during observation and naming of familiar tools. Neuroimage, 6(4), 231-236.

Hughes, D., Woodcock, J., \& Funnell, E. (2005). Conceptions of objects across categories: childhood patterns resemble those of adults. British Journal of Psychology, 96, 1-19.

Jonhnson-Frey, S. H. (2004). The neural bases of complex tool use in humans. Trends in cognitive sciences, 8(2), 71-79.

Kellenbach, M. L., Brett, M., \& Patterson, K. (2003). Actions speak louder than functions: the importance of manipulability and action in tool representation. Journal of Cognitive Neuroscience, 15(1), 30-46.

Kemler Nelson, D. G. (1995). Principle-based inferences in young children's categorization: Revisiting the impact of function on the naming of artifacts. Cognitive Development, 10(3), 347-380.

Kemler Nelson, D. G., Chan Egan, L., \& Holt, M. B. (2004). When children ask, "what is it ?" What do they want to know about artifacts? Psychological Science, 15(6), 384-389.

Kemler Nelson, D. G., Frankenfield, A., Morris, C., \& Blair, E. (2000). Young children's use of functional information to categorize artifacts: three factors that matter. Cognition, 77, 133-168.

Kemler Nelson, D. G., Russell, R., \& Jones, K. (2000). Two-year-olds will name artifacts by their functions. Child Development, 71(5), 1271-1288.

Lautrey, J. (1990). Esquisse d'un modèle pluraliste du développement cognitif. In M. Reuchlin, J. Lautrey, C. Marendaz \& T. Ohlmann (Eds.), Cognition: l'individuel et l'universel (pp. 185-216). Paris: PUF.

Lautrey, J. (2003). A pluralistic approach to cognitive differentiation and development. In T. Lubart (Ed.), Models of intelligence: International perspectives (pp. 117-131). Washington, DC: A.P.A. Press.

Lautrey, J., \& Caroff, X. (1997). Variability and cognitive development. Polish Quarterly of Developmental Psychology, 2(2), 71-89. 
Laws, K. R., Humber, S. A., Ramsey, D. J. C., \& McCarthy, R. A. (1995). Probing sensory and associative semantics for animals and objects in normal subjects. Memory, 3(3/4), 397-408.

Liu, J., Golinkoff, R. M., \& Sak, K. (2001). One cow does not an animal make: young children can extend novel words at the superordinate level. Child Development, 72(6), 1674-1694.

Madole, K. L., Oakes, L. M., \& Cohen, L. B. (1993). Developmental Changes in Infants' Attention to Function and Form-Function Correlations. Cognitive Development, 8, 189-209.

Mandler, J. M. (1992). How to build a baby: II. Conceptual primitives. Psychological Review, 99(4), 587-604.

Mandler, J. M. (2000). Perceptual and conceptual processes in infancy. Journal of Cognition and Development, 1, 3-36.

Markman, E. M., Cox, B., \& Machida, S. (1981). The standard object-sorting task as a mesure of conceptual organization. Developmental Psychology, 17(1), 115-117.

Markman, E. M., \& Hutchinson, J. E. (1984). Children's sensitivity to constraints on word meaning: Taxonomic versus thematic relations. Cognitive Psychology, 16, 1-27.

Myung, J.-Y., Blumstein, S. E., \& Sedivy, J. C. (in press). Playing on the typewriter, typing on the panio: Manipulation knowledge of objects. Cognition, 1-21.

Namy, L. L., \& Gentner, D. (2002). Making a silk purse out of two sow's ears: young children's use of comparison in category learning. J Exp Psychol Gen, 131(1), 5-15.

Nelson, K. (1983). The derivation of concepts and categories from event representations. In E. K. Scholnick (Ed.), New trends in conceptual representation: Challenges to Piaget's theory? (pp. 129-149). Hillsdale, N.J.: Erlbaum.

Nelson, K. (1985). Making sense. The acquisition of shared meaning. New York: Academic Press.

Osborne, J. G., \& Calhoun, D. O. (1998). Themes, taxons, and trial types in children's matching to sample: methodological considerations. Journal of Experimental Child Psychology, 68(1), 35-50.

Quinn, P. C., Eimas, P. D., \& Rosenkrantz, S. L. (1993). Evidence for representations of perceptually similar natural categories by 3-month-old and 4-month-old infants. Perception, 22(4), 463-475.

Rosch, E., Mervis, C. B., Gray, W. D., Johnson, D. M., \& Boyes-Braem, P. (1976). Basic objects in natural categories. Cognitive Psychology, 38, 495-553.

Sartori, G., \& Job, R. (1988). The oyster with four legs: a neuropsychological study on the interaction of visual and semantic information. Cognitive Neuropsychology, 5(1), 105-132.

Scheuner, N., \& Bonthoux, F. (2004). La construction des catégories surordonnées chez l'enfant: Utilisation différentielle des indices perceptifs et contextuel dans le domaine du vivant et du non-vivant. Bulletin de Psychologie, 57, 105-109.

Siegler, R. S., \& Jenkins, E. (1989). How children discover new strategies. Hillsdale: Erlbaum.

Siegler, R. S., \& Shipley, C. (1995). Variation, selection and cognitive change. In G. S. Halford (Ed.), Developing cognitive competence. New approaches to process modelling (pp. 31-76). Hillsdale, NJ: Erlbaum.

Smiley, S. S., \& Brown, A. L. (1979). Conceptual preference fot thematic ot taxonomic relations : A nonmonotonic age trend from preschool to old age. Journal of Experimental Child Psychology, 28, 249-257. 
Waxman, S. R., \& Gelman, R. (1986). Preschoolers' use of superordinate relations in classification and language. Cognitive Development, 1, 139-156.

Waxman, S. R., \& Namy, L. L. (1997). Challenging the notion of a thematic preference in young children. Developmental Psychology, 33(3), 555-567.

Wisniewski, E. J., \& Bassok, M. (1999). What makes a man similar to a tie? Stimulus compatibility with comparison and integration. Cognit Psychol, 39(3-4), 208-238.

\section{ABSTRACTS}

A differential approach of concepts formation considers that concepts can derive from similarity and contextual relations, their involvement varying according to individuals and domains. The following experiment was designed to test this differential hypothesis. Session 1 investigated individual differences in 3 year-old children with a matching task contrasting a thematic match and a basic-level taxonomic match. In spite of a taxonomic bias, children's sensitivity to each relation ordered on a taxonomic-thematic continuum. In session 2, taxonomic performances in superordinate categorization were analyzed as a function of children's sensitivity and objects domain. Children most sensitive to basic level taxonomic relations categorized better living things than non-living things at the superordinate level. On the contrary, no difference between domains was observed for children most sensitive to thematic relations. Moreover, superordinate performances for living things appeared correlated to choices in session 1, unlike for non-living things. Overall, results supported a differential approach of conceptual development.

Une approche différentielle de la formation des concepts envisage que ceux-ci dérivent des relations de similarité et de proximité contextuelle entre les objets, leur implication variant selon les individus et le domaine. Pour tester cette hypothèse, une tâche d'appariement opposant un associé thématique et un associé taxonomique de niveau de base a d'abord été proposée à des enfants de 3 ans. Malgré un biais taxonomique, les choix s'ordonnent sur un continuum thématique - taxonomique. Dans une seconde phase, les performances en catégorisation surordonnée sont analysées selon la sensibilité à chaque relation en phase 1 et le domaine. Les enfants les plus sensibles aux relations taxonomiques montrent un avantage pour le vivant mais les scores des enfants les plus sensibles aux relations thématiques ne diffèrent pas selon le domaine. En outre pour le vivant, les performances surordonnées sont corrélées avec les choix en phase 1 ; aucun lien n'est observé pour le non-vivant. Dans l'ensemble, ces résultats appuient un modèle différentiel du développement conceptuel.

INDEX

Keywords: Development, concepts, individual differences

\section{AUTHORS}

\section{SOLÈNE KALÉNINE}

Laboratoire de Psychologie et NeuroCognition, CNRS UMR 5105, Université Pierre Mendès France, PO Box 47, F-38040 Grenoble Cedex 9. France 
FRANÇOISE BONTHOUX

so_kalenine@hotmail.fr 